\title{
Evaluation and Enlightenment of Tanzanian Student Loan Policy
}

\author{
Tao Feng ${ }^{1}$, Zhigang $\mathrm{Gao}^{2,}$ *
}

\author{
${ }^{1}$ Shanghai University of Political Science and Law \\ ${ }^{2}$ Shanghai University of Political Science and Law \\ *Corresponding author. Email: gaozhigang@shupl.edu.cn
}

\begin{abstract}
Tanzania is a developing country, but its higher education have a great development in recent years. The student loan policy of Tanzania has certain characteristics in the design of demand, application conditions and highest limit reimbursement, etc, it also has some bad, such as limited funding, unreasonable distribution in different discipline. As developing countries, China and Tanzania have similar conditions, China can learn some from Tanzania, such as mixed style loan, loan coverage, the unified application system of student loans, etc.
\end{abstract}

Keywords: Student loan, Tanzania, Mixed style loan.

\section{坦桑尼亚助学贷款政策评价及启示}

\author{
冯涛 ${ }^{1}$, 高志刚 ${ }^{2,}{ }^{*}$
}

1 上海政法学院, 上海, 中国

2 上海政法学院, 上海, 中国

*通讯作者. 邮箱: gaozhigang@shupl.edu.cn

\section{中文摘要}

坦桑尼亚虽然是发展中国家，但高等教育近年来有较大发展，其助学贷款政策在需求满足、申请条件和最高还 款限制等方面的设计有一定特色，也存在着资金有限，发放学科不合理的缺点。中国和坦桑尼亚同为发展中国 家, 具有相似的国情, 可以在混合型贷款、贷款发放项目、建立助学贷款统一的申请系统等方面参考坦桑尼亚 的经验。

关键词: 助学贷款; 坦桑尼亚; 混合型贷款

\section{1. 引言}

坦桑尼亚过去的高等教育较为落后, 经过数十年 的发展, 近年来其高等教育有了长足进步, 突出表 现在年轻人的受教育机会不断扩大, 受教育的性别 不平等有了极大的改善, 同时中坦高等教育合作也 取得了较大的成果。坦桑尼亚和中国一向关系良好, 中国援建的坦赞铁路更是当时中非合作的典范, 自 中国提出“一带一路”倡议以来, 坦桑尼亚也积极参
与到这个进程中来，以发展自己的贸易和经济，最 近举行的“一带一路”高峰论坛, 坦桑尼亚也派部长 代表总统参与, 并与中国签署了相关协议。教育领 域的合作与援助不像经济领域的援助那样有直接效 益, 但教育合作与援助也有着自己的作用, 包括培 养与中国友好的人才, 扩大文化影响等, 这些因素 最终也会传导到受助国的各个领域, 发挥着独特的 作用, 因此, 了解像坦桑尼亚这样的“一带一路”沿 
线国家的教育政策，对中国“一带一路”战略的推进 是有着特殊的意义的, 助学贷款政策也不例外, 本 文介绍、分析和评价了坦桑尼亚近年来的助学贷款 政策，总结了对中国助学贷款政策的借鉴，这些也 可能为今后两国在助学贷款政策领域的合作提供些 许参考。

\section{2. 坦桑尼亚助学贷款政策}

\section{1. 管理和经办机构}

坦桑尼亚目前的助学贷款政策由依照法律成立 的专门机构一一高等教育学生贷款委员会 (以下简 称学贷委) 负责拟定并贯彻执行, 学贷委职责被设 定为: 向坦桑尼亚境内和境外的 (一般是基于两国 的双边协议在国外学习) 公立、私立高等教育机构 录取的合格和有经济需要的具有坦桑尼亚国籍的学 生发放贷款和助学金, 专业证书课程和本科课程的 学生在国内外学习都可以获得助学贷款, 而硕士和 博士课程的学生则必须是在国内学习, 同时必须是 高等教育机构的学术性职员才可以获得助学贷款; 回收以前年度发放的贷款以便循环使用; 与主要的 助学贷款政策参与者进行合作, 包括高等教育机构、 雇主等; 向政府提出贷款发放和回收的有关建议。 助学贷款的分配和支付则由学贷委下属的贷款分配 和支付管理局进行。法案还赋予学贷委管理和监督 助学贷款发放和回收的整个过程, 允许学贷委决定 每个年度可以获得助学贷款的最多学生数量、贷款 利率以及和回收贷款有关的其他事项。

\section{2. 利率}

最早的助学贷款是零利率, 从 2011-2012 学年所 有贷款开始执行 6\%的年利率, 并且从 2014-2015 学 年, 所有从 1994-1995 学年开始的助学贷款都将回 溯性地执行 $6 \%$ 的年利率, 这样做的目的是为了使 这个贷款项目可持续发展。

\section{3. 贷款的项目}

目的是以贷款的方式, 资助那些已经获得经认证 的高等教育机构入学许可的有经济需要的学生, 以 便他们顺利完成高等教育。目前学贷委发放六项贷 款, 包括: 食宿费贷款、学费贷款、书籍文具费贷 款、教员特殊要求费贷款、田野实践训练费贷款、 研究费贷款。学费贷款、教员特殊要求费贷款、田 野实践训练费贷款基于财富评分发放, 食宿费贷款、 书籍文具费贷款、研究费贷款和财富评分无关。学 贷委会定期根据物价变动情况调整食宿费贷款的数 额。

\section{4. 获得助学贷款的学生范围及资格}

能够获得助学贷款的学生包括: 贫困的孤儿; 有 残疾的贫困申请者或其父母是残疾人的申请者; 失
去一个父母的贫困申请者; 来自贫困家庭的申请者。

从 2015-2016 学年的情况看, 获得贷款的资格则 是: 必须是坦桑尼亚人; 必须通过在线申请系统申 请了助学贷款; 必须被一个认证的高等教育机构录 取并属于全日制学习身份; 必须已经通过了必要的 考试, 能够维持就学持续性; 没有获得其他机构的 全部资助; 必须是完成了中等教育, 没有被雇佣, 第一次直接申请助学贷款; 根据坦桑尼亚和其他国 家的双边协议在海外就读的学生; 就读最长六年学 制的坦桑尼亚开放大学的学生只能获得两类助学贷 款, 即学费和书本文具费贷款; 就读每一类专业的 贷款申请人分别有不同的适用条件, 但整体上照顾 科学和工程领域的申请人, 这应该是考虑到坦桑尼 亚国家经济和技术发展的需要。

\section{5. 贷款数额的决定}

坦桑尼亚贷款数额的决定参考了美国助学贷款 额度的确定思路, 也是采用一个公式来决定。基本 的思路也是上大学的成本减去学生所能为上大学付 出的经济资源, 但是经济资源会根据孤儿、残疾、 单身父母这些因素来加以调节, 即符合这三种情况 的会把经济资源打折。

\section{6. 还款规定和保障}

借款学生毕业后有两年的宽限期, 然后开始还 款，每月还款不超过月收入的 $15 \%$ ，如果是自我雇 佣的借款学生, 则每月归还的贷款不超过 10 万坦桑 尼亚先令, 还款通常为 10-15 年, 也可以选择分期 定额还款。根据贷款数额可以选择实物担保和担保 人担保。

\section{7. 助学贷款申请系统}

从 2011-2012 学年开始, 学贷委开始使用一个在 线贷款申请系统来处理助学贷款的申请。申请人在 系统里打印出申请表和贷款协议, 签好字, 附带上 需要的文件, 通过特快专递或者挂号信寄给学贷委。 申请人第一次申请需要支付 3 万坦桑尼亚先令的申 请费。

\section{8. 学生获得两个高教机构录取或转学}

如果学生要进入两个或以上高教机构就读, 则无 法获得助学贷款, 因此而导致的一切延迟获得或无 法获得助学贷款的问题由学生个人承担。如果学生 先进入一个高教机构, 然后转学, 则前一个就读的 高教机构需要把助学贷款退回到学贷委, 然后才能 转到新就读的学校。

\section{9. 不满助学贷款额度的救济}

申请人如果不满意学贷委核准的助学贷款数额 
可以提出上诉，每次上诉须支付 1 万坦桑尼亚先令 上诉费，上诉必须通过高教机构的助学贷款管理人 员汇总, 然后提交到学贷委, 上诉必须在开学后 90 天内进行。

以上是坦桑尼亚助学贷款的制度设计, 虽然坦桑 尼亚是一个发展中国家，但由于其和英国历史上的 联系, 教育政策设计上也能参考一定的国际经验等 因素的影响, 其官办政策性助学贷款政策的制度设 计比较复杂和细化, 很大程度上考虑了借款学生的 利益和诉求, 具有较高的政策设计水平。

\section{3. 坦桑尼亚助学贷款政策评价}

\section{1. 较有特色的一些设计}

坦桑尼亚目前共发放六项贷款项目, 包括: 食宿 费、学费、书籍文具费、教员特殊要求费、田野实 践训练费、研究费贷款。其中前三项是普遍发放所 有借款学生的, 可称之为基本项目; 后三项则是只 发放某些特定领域有这方面需要的学生, 可称之为 特殊项目, 在世界上实行助学贷款的国家中, 这个 覆盖项目是比较充分的, 同时基本项目和特殊项目 的分类设计, 兼顾了不同领域学生的实际需要, 同 时能节省一定的资金, 是比较科学的制度设计, 在 世界上其他国家的助学贷款政策设计中都比较少 见。

坦桑尼亚是发展中国家, 社会经济环境相对比较 落后, 助学贷款运行所需要的一些社会经济条件如 税收系统、收入申报、财产申报等都不太完善, 但 其助学贷款政策通过一些巧妙的设计回避了这些不 足的地方, 在申请条件和额度决定方面尤其是这样。 坦桑尼亚贷款数额的决定沿袭了美国助学贷款额度 的确定思路, 也是采用一个公式来决定, 基本的思 路也是上大学的成本减去学生所能为上大学付出的 经济资源, 但美国的税收系统等条件较为发达, 因 此学生所能为上大学付出的经济资源可以通过一个 表格申报比较准确地度量出来, 而发展中国家这方 面很难度量 (中国也不例外, 这也是中国迄今为止 没有一个明确的助学贷款准入条件的主要原因）, 但坦桑尼亚采用把申请人在大学前一级教育机构所 付的学费作为衡量申请人支付大学学费的能力指 标, 可以较好地解决无法量化学生能为上大学付出 的经济资源的问题, 当然这样做还会存在一定的误 差, 但已经算解决的比较好的了。

世界上当前主要有两种助学贷款, 一种是传统的 按揭型贷款, 一种是按收入比例还款型贷款, 坦桑 尼亚采取的是“混合型还款”, 即传统的按揭型贷款, 加入按收入比例还款因素, 每月还款额是按照按揭 贷款固定下来的, 但是有最高还款限额的限制, 借 款学生每月还款不超过月收入的 $15 \%$, 如果是自我 雇佣的借款学生, 则每月还款不超过 10 万坦桑尼亚 先令, 如果收入下降, 每月还款额超过了最高限额, 那么就可以按照收入的 $15 \%$ 比例还款, 这保证了借
款学生的还款负担是可控的, 较好地实现了两种贷 款模式的统一, 既兼顾了本国发展中国家的国情, 也控制了借款学生的还款负担。

坦桑尼亚通过立法形式建立了统一的助学贷款 管理机构——学贷委, 统一管理全国的助学贷款事 务, 赋予了该机构较强的法律地位, 保障了助学贷 款的顺利运行。从 2011-2012 学年开始, 学贷委开 始使用一个在线贷款申请系统来接受借款学生的申 请, 这样做的好处体现在: 一是可以尽量无纸化运 作，带来了效率的提升; 二是可以在全国范围内对 贫困学生进行排名, 消除地域带来的差异; 三是可 以统一积累储存助学贷款的相关数据, 为今后的政 策检讨、反思和研究提供大数据基础。

\section{2. 存在的不足}

坦桑尼亚毕竟是一个较为落后的发展中国家, 其 助学贷款政策设计上资金来源于政府财政资金，而 发展中国家普遍的公共财政紧张导致了坦桑尼亚助 学贷款的资金不足, 从 2012-2015 这三个学年来看, 每年的平均助学贷款发放比率 (发放人数除以申请 人数）为 $55 \%$, 即 167,306 人申请, 最终只发放给 了 92,064 人。贷款发放数额为 $323,916,822,837$ 坦 桑尼亚先令, 约合 906,967,104 元人民币, 导致这一 现象的原因很大程度上是因为助学贷款资金有限

助学贷款资金不足还带来了另一个问题, 由于总 量有限, 必须取舍和倾斜, 这导致了贷款发放学科 的不平衡和不合理, 大概出于发展高技术行业和经 济的考虑, 当前的助学贷款发放侧重理工科学生, 忽视了人文社会科学, 包括管理科学, 这不能不说 是另一个政策的不足。经济和社会的发展是一个整 体, 需要协调共进, 片面强调某些学科人才的培养, 对坦桑尼亚这种发展中国家来说, 恐怕很难奏效, 最终可能是强调的学科也没发展起来, 其他学科反 而滞后了，但受制于总体资金不足的困扰，这个问 题也不易解决。

\section{4. 对中国的启示}

\section{1. 贷款额度实行基本项目加特殊项目}

中国的助学贷款目前本科生每年 8000 元, 研究 生每年 12000 元的额度基本只够覆盖学费的需要, 生活费的方面, 现行的资助政策设计的是用助学金 来覆盖, 但助学金每年只有 2000-3000 元的额度, 且名额有限, 获得的学生覆盖面也不是很广, 随着 社会和教育的发展, 在校学生的经济需求却在不断 拓展, 包括校外培训、课外调研、购买课外参考资 料等等, 这些都是现有的助学贷款无法覆盖的, 可 以在目前的学费贷款的基础上（学费贷款可以看作 基本项目），增加一些其他的特殊项目，但不是普 遍覆盖的, 根据就读学校、专业、成绩等来有选择 的覆盖。 


\section{2. 整合助学贷款申请到一个系统}

当前中国的助学贷款分为生源地助学贷款和校 园地助学贷款, 生源地助学贷款由国家开发银行办 理, 校园地助学贷款则由学校所在地中标的商业银 行办理, 生源地助学贷款基本上是在国开行统一的 助学贷款系统里办理的, 而校园地助学贷款则比较 分散, 没有一个统一的助学贷款系统来管理。未来 可整合已有的助学贷款数据到一个统一的系统, 设 定统一的助学贷款信息标准, 未来的助学贷款新的 申请也在这个新的助学贷款系统里来完成, 为助学 贷款政策积累大数据基础。

\section{3. 出台专门的学生资助立法}

目前的学生资助政策都是以部门文件的方式起 指导作用的, 一般是教育部、财政部、人民银行总 行、银监会一起制定各种政策文件, 下发各地遵照 执行, 中国的学生资助政策也运行了将近 20 年了, 各方面的政策已基本稳定并趋于完善, 另外, 作为 世界第一人口大国, 也可能是第一学生资助大国, 客观上也需要一部专门的学生资助法律, 事实上, 不止是坦桑尼亚, 世界上很多国家都出台了专门的 助学贷款或学生资助法案, 有发达国家, 也有发展 中国家, 专门立法的好处在于: 一是从全社会的角 度通过立法的形式凸显了学生资助的重要性; 二是 法律更有强制力, 可以督促各参与主体更好地配合 相应的工作, 如助学贷款的发放和回收等。

\section{REFERENCES}

[1] F.M. Msigwa, Widening participation in higher education: a social justice analysis of student loans in Tanzania, Higher Education, vol.72, no.4, 2016, pp.541-556. DOI:https://doi.org/10.1007/s10734-016-0037-5

[2] V.Makulilo, Access Denied? Examining the Loans Board Facility for Higher Learning Students in Tanzania, CEU Political Science Journal, vol.6, no.2, 2011, pp.254-285. DOI: https://doi.org/10.2139/ssrn.1846312

[3] V.R. Nyahende, Implementations of the Best Practices in Repayment, the Way to Improve Collections of the Due Students'Loans in Tanzania, Higher Education Studies, vol.6, no.1, 2016, DOI:https://doi.org/10.5539/hes.v6n1p60

[4] V.R. Nyahende, A.N. Bangu1, B.C. Chakaza, Survey on the Assessment of the Current Actual Expenses Incurred by Students on the Meals and Accommodation within and around the Campuses: The Case of Tanzania Higher Education Students'Loans Beneficiaries, Higher Education
Studies, vol.5, no.4, 2015, pp.56-85. DOI:https://doi.org/10.5539/hes.v5n4p56 